\title{
INFLUÊNCIA DA MICROBIOTA INTESTINAL NA DOENÇA HEPÁTICA GORDUROSA NÃO ALCOÓLICA
}

\section{ARTIGO DE REVISÃO}

\author{
ALMEIDA, Isadora Barbosa de ${ }^{1}$ \\ BARROSO, Wermerson Assunção ${ }^{2}$
}

GONÇALVES, Caroline Amélia ${ }^{3}$

ALMEIDA, Isadora Barbosa de. BARROSO, Wermerson Assunção. GONÇALVES, Caroline Amélia. Influência da microbiota intestinal na Doença Hepática Gordurosa Não Alcoólica. Revista Científica Multidisciplinar Núcleo do Conhecimento. Ano 05, Ed. 11, Vol. 11, pp. 14-20. Novembro de 2020. ISSN: 24480959, Link de acesso: https://www.nucleodoconhecimento.com.br/saude/microbiotaintestinal

\section{RESUMO}

A microbiota intestinal está em equilíbrio em um ser humano saudável, permitindo a manutenção adequada e, consequentemente, levando a homeostase. Há uma relação de troca entre o hospedeiro, que fornece um ambiente adequado e nutrientes, e sua microbiota, responsável por sintetizar e auxiliar na digestão de diversos aminoácidos essenciais e vitaminas. $O$ desequilíbrio pode ocorrer tanto por diminuição ou aumento exagerado no número de bactérias, quanto por perda da diversidade dessas bactérias, o que se denomina disbiose. Quando ocorre a disbiose tem-se um ambiente favorável para o desenvolvimento de diversas doenças, entre elas a doença hepática gordurosa não alcoólica (DHGNA). Nesse sentido, foi realizada uma busca de artigos científicos

\footnotetext{
${ }^{1}$ Graduanda em Biomedicina pela Universidade Ceuma.

2 Docente do Curso de Medicina, Faculdade ITPAC Santa Inês.

${ }^{3}$ Docente do Curso de Biomedicina, pela Universidade Ceuma.
} 
publicados nos últimos cinco anos na base de dados PubMed. Após incluir as palavras-chaves e o filtro para ensaios em humanos, foram encontrados 26 artigos, dos quais 13 foram selecionados de acordo com sua relevância para essa revisão de literatura. Dessa forma, foi possível constatar que os estudos sobre as variações de bactérias com potencial patogênico, relacionado ao agravo ou surgimento da DHGNA, ainda são limitados e contraditórios. Havendo a necessidade de estudos maiores e randomizados para obterem dados mais concretos, a fim de beneficiar o paciente acometido por essa alteração metabólica.

Palavras-chave: Microbioma, gastrointestinal, fígado gorduroso.

\section{INTRODUÇÃO}

A doença hepática gordurosa não alcoólica (DHGNA) é uma das principais causas de doenças hepáticas crônicas atualmente no mundo. É caracterizada por uma quantidade de gordura no fígado superior à $5 \%$ do peso desse órgão. Sabe-se que as causas para esse quadro são diversas, tendo associação com a obesidade, diabetes mellitus tipo 2, doenças cardiovasculares e doenças renais crônicas (DONG et al., 2019; WANG et al., 2019).

Além disso, por meio de estudos, descobriu-se que a DHGNA está intimamente ligada à disbiose, que é caracterizada por um desequilíbrio na microbiota intestinal (WANG et al., 2019).

A DHGNA apresenta uma prevalência global de $25 \%$ na população adulta, atingindo taxas bem mais elevadas em determinados países, como o Japão, onde ultrapassa $50 \%$ da população, e na Itália, onde ocorre em cerca de $70 \%$ dos italianos. No entanto, não se sabe ao certo se a DHGNA é a causa ou a consequência de um comprometimento do estado metabólico (MARCHISELLO et al., 2019).

Em um ser humano saudável a microbiota intestinal está em equilíbrio, permitindo a manutenção adequada do estado metabólico e, consequentemente, levando à homeostase. Há uma relação de troca entre o hospedeiro, que fornece um ambiente 
adequado e nutrientes, e sua microbiota, responsável por sintetizar e auxiliar na digestão de diversos aminoácidos essenciais e vitaminas (WANG et al., 2019).

Nesse sentido, o desequilíbrio pode ocorrer tanto por diminuição ou aumento exagerado no número de bactérias, quanto por perda da diversidade dessas bactérias. Quando ocorre a disbiose, tem-se um ambiente favorável para o desenvolvimento de diversas doenças, entre elas a DHGNA (WANG et al., 2019).

Outrossim, a microbiota intestinal humana é responsável por várias funções metabólicas, entre elas a síntese de vitaminas $\mathrm{B}$ e K, auxílio na digestão de alimentos e síntese de aminoácidos essenciais. Além disso, ele atua na linha de defesa contra patógenos e toxinas, por meio da formação de uma barreira composta por antimicrobianos, como a bacteriocina (SIDHU et al., 2017).

Por esses motivos, quando a microbiota sofre uma grande alteração, é possível observar um desequilíbrio em várias funções metabólicas, predispondo o indivíduo a diversas doenças (SIDHU et al., 2017).

As alterações na flora bacteriana intestinal relacionadas com a DHGNA faz com que haja uma translocação bacteriana intestinal, levando a um aumento no fornecimento de polissacarídeos, ácidos graxos livres e outras toxinas no fígado, por meio da veia porta (SIDHU et al., 2017).

Além disso, observa-se uma maior quantidade de bactérias Escherichia coli nessa condição, sendo elas as responsáveis por fermentar carboidrato e produzir etanol endógeno, o que leva a um aumento periférico de álcool, gerando uma piora no quadro da DHGNA (SIDHU et al., 2017).

Desse modo, a presença pesquisa objetivou, através de uma revisão de literatura, investigar possíveis alterações na microbiota intestinal que podem se relacionar com o agravo ou o surgimento da doença hepática gordurosa não alcóolica. 


\section{METODOLOGIA}

Esse estudo trata-se de uma revisão de literatura, de caráter exploratório. Foi elaborado a partir de uma pesquisa de artigos científicos, entre os meses de março e setembro de 2020, na base de dados PubMed (US National Library of Medicine National Institutes of Health), utilizando os descritores "gatrointestinal microbiome", "fatty liver" e "physiopathology", retirados da Biblioteca de Descritores em Ciências da Saúde (DeCS).

Foram utilizados artigos cujas palavras-chaves estavam relacionadas ao acometimento da doença em seres humanos. Na base de dados, encontrou-se 26 artigos científicos publicados entre os anos de 2015 e 2020, onde foram selecionados 13 para compor a revisão de literatura, sendo que todos estes foram de língua inglesa. O ano que concentrou a maior produção literária acerca do tema desta revisão foi 2019, que detêm quatro artigos. Os demais artigos foram publicados entre os anos de 2015 e 2018, sendo dois artigos em cada ano, com exceção à 2016, que teve três.

\section{RESULTADOS E DISCUSSÃO}

A barreira intestinal é considerada o primeiro mecanismo de defesa do organismo contra a invasão de patógenos. Ela é formada por um revestimento de muco e células especializadas que contam com junções intercelulares que permitem um controle do fluxo de substâncias e produtos (ARAB et al., 2018).

No entanto, o principal regulador do mecanismo de defesa é a microbiota intestinal. Não se sabe ao certo quais são os mecanismos relacionados, mas a alteração da microbiota está associada ao desenvolvimento da DHGNA. É conhecido que essa associação está relacionada a um aumento excessivo do crescimento bacteriano, juntamente a uma alteração da flora bacteriana intestinal, o que facilita a passagem das bactérias e seus produtos para o fígado (ARAB et al., 2018).

Ainda é limitado e contraditório o número de estudos que evidenciam e especificam as alterações da microbiota intestinal na DHGNA. Contudo, nas técnicas de 
sequenciamento foram relatados o aumento de Bacteroides e uma diminuição de Firmicutes se comparado a indivíduos saudáveis, enquanto que pelo qPCR foi demostrado a diminuição de Bacteroides (BEST et al., 2015).

Assim, a aparente falta de mudanças consistentes na composição da microbiota intestinal na DHGNA é ainda exemplificada por uma super-representação do gênero Escherichia da família Enterobacteriaceae em indivíduos com DHGNA ou nenhuma diferença na abundância de Escherichia em pacientes com DHGNA, em comparação com indivíduos com esteatose simples ou saudáveis (BEST et al., 2015).

As fezes de pacientes com DHGNA apresentam menor quantidade de Bacterioidetes quando comparadas a pessoas saudáveis. Além disso, apresentam uma redução de Faecalibacterium (Firmicutes) e Anaerosporobacter (Firmicutes), mas um aumento de Parabacteroides (Bacteroidetes) e Allisonella (Firmicutes) na microbiota do intestino. Ainda, tem-se uma diminuição de Ruminococcus, F. prausnitzii e Coprococo no intestino de pacientes com DHGNA (WANG et al., 2019).

Não obstante, a microbiota intestinal é responsável por regular a homeostase dos ácidos biliares por meio da biotransformação (desconjugação, desidroxilação, oxidação e dessulfatação) (WANG et al., 2019).

A desconjugação é realizada principalmente por Bacteoides, Lactobacillus, Bifidobacterium, Clostridium e Listeria, por meio da produção de hidrolases de sal biliar, que desconjugam grupos taurina e glicina de ácidos biliares, alterando o metabolismo (WANG et al., 2019).

A desidroxilação está relacionada aos grupos Clostridium e Eubacterium, responsáveis pela conversão dos ácidos biliares primários em secundários, sendo essa, uma etapa essencial para a ativação da função dos ácidos (WANG et al., 2019).

Quanto à oxidação, os grupos relacionados são Bacteroides, Clostridium, Eubacterium, Escherichia, Eggerthella, Peptostreptococcus e Ruminococcus, que atuam gerando hidroxisteróides desidrogenades, convertendo os ácidos biliares tóxicos para uma forma mais solúvel (WANG et al., 2019). 
Por fim, bactérias como Clostridium $s p$ produzem sulfatases que realizam a dessulfatação dos ácidos biliares, o que facilita sua reabsorção. Quando há o desequilíbrio da flora, há perda de função das bactérias e, consequentemente, os ácidos biliares não atuarão de forma eficiente, gerando um desequilíbrio da homeostase (WANG et al., 2019).

O estudo indica uma relação entre a disbiose e a DHGNA, relacionando-os com o mau funcionamento da sinalização dos ácidos biliares. Este composto é produzido pelos hepatócitos por meio da oxidação do colesterol e tem grande importância na absorção de gordura, agindo de forma a emulsificar e solubilizar tal substância (WANG et al., 2019).

Além disso, os ácidos biliares agem sinalizando moléculas e regulando o metabolismo de lipídios e glicose, uma vez que ativam receptores ligados a essa função, como o farnesóide X (FXR) e a proteína Takeda G acoplada ao receptor 5 (TGR5) (WANG et al., 2019).

Assim, a disbiose, além de levar ao desenvolvimento da DHGNA, gera uma perturbação na homeostase dos ácidos biliares. Isso ocorre porque a microbiota intestinal é responsável por converter o ácido biliar primário, produzido pelo fígado, em ácido biliar secundário, que promove a absorção de lipídios e algumas vitaminas, além de sinalizar moléculas nos tecidos a fim de modular o metabolismo de lipídios e carboidratos para gerar energia (BOURSIER et al.,2016; WANG et al., 2019).

Outra função importante dos ácidos biliares está relacionada ao aumento da sensibilidade à insulina e redução da gliconeogênese. Por fim, dentre todas as funções conhecidas dos ácidos biliares, destaca-se também os seus efeitos antimicrobianos e seus efeitos inibitórios indiretos sobre o crescimento excessivo de bactérias, gerando um equilíbrio da microbiota intestinal. Dessa forma, é possível notar que existe uma relação intima entre disbiose, um desequilíbrio na função dos ácidos biliares e DHGNA (WANG et al., 2019). 
Nesse sentido, em casos em que essa função está prejudicada, temos uma modificação da microbiota intestinal, o que leva a disbiose e, consequentemente, ao desenvolvimento da doença hepática gordurosa não alcoólica (WANG et al., 2019).

Apesar da disparidade dos resultados, percebe-se que a disbiose influencia diretamente na DHGNA, uma vez que o aumento excessivo de bactérias produtoras de etanol pode estar associado ao aumento dos níveis de etanol circulantes. A produção endógena de etanol pode, por sua vez, contribuir para a formação de ácidos graxos livres e estresse oxidativo, ressaltando ainda mais o papel potencial das bactérias produtoras de etanol na patogênese da DHGNA (WANG et al., 2019).

Entretanto, faz-se necessário estudos em larga escala para identificar alterações na composição da microbiota em pacientes com esteatose simples comparados a pacientes com DHGNA, correlacionando a presença ou ausência de obesidade, uma vez que a literatura relata a interligação da obesidade nas alterações da microbiota intestinal (BEST et al., 2015). Com isso, fica clara a relação entre a disbiose e a ocorrência da DHGNA independente de anormalidade metabólica (WANG et al., 2019).

Dessa forma foi possível constatar que os estudos ainda são limitados e contraditórios, havendo a necessidade de estudos maiores e randomizados para obterem dados mais concretos, a fim de beneficiar o paciente acometido por essa alteração metabólica.

\section{CONCLUSÃO}

Essa pesquisa foi salutar ao ressaltar a presença de disbiose em pacientes com doença hepática gordurosa não alcoólica. O surgimento ou o agravo dessa doença está relacionada à variação da microbiota intestinal. A maioria dos autores identificam a DHGNA como doença secundária, sendo consequência de uma patologia préestabelecida. Entretanto, não foi possível identificar a correlação entre o agravo ou o surgimento com outras patologias, somente apontar que na maioria dos casos de pacientes com DHGNA há uma outra patologia associada, não sabendo quem é 
primária e quem é secundária. Portanto, mais pesquisas específicas devem ser desenvolvidas, sobretudo ensaios clínicos que correlacionem a DHGNA com a variação da microbiota intestinal, para que as controvérsias existentes atualmente sejam elucidadas.

\section{REFERÊNCIAS}

ACHARYA, Chathur; BAJAJ, Jasmohan S. Gut microbiota and complications of liver disease. Gastroenterology Clinics, v. 46, n. 1, p. 155-169, 2017.

ARAB, Juan P.; MARTIN-MATEOS, Rosa M.; SHAH, Vijay H. Gut-liver axis, cirrhosis and portal hypertension: the chicken and the egg. Hepatology international, v. 12, n. 1, p. 24-33, 2018.

BOURSIER, Jerome; DIEHL, Anna Mae. Nonalcoholic fatty liver disease and the gut microbiome. Clinics in Liver Disease, v. 20, n. 2, p. 263-275, 2016.

DA SILVA, Hannah E. et al. Nonalcoholic fatty liver disease is associated with dysbiosis independent of body mass index and insulin resistance. Scientific reports, v. 8 , n. 1, p. 1-12, 2018.

DONG, Tien S.; JACOBS, Jonathan P. Nonalcoholic fatty liver disease and the gut microbiome: Are bacteria responsible for fatty liver?. Experimental Biology and Medicine, v. 244, n. 6, p. 408-418, 2019.

FERRELL, Jessica M.; CHIANG, John YL. Understanding bile acid signaling in diabetes: From pathophysiology to therapeutic targets. Diabetes \& metabolism journal, v. 43, n. 3, p. 257-272, 2019.

LAU, E.; CARVALHO, D.; FREITAS, P. Gut microbiota: association with NAFLD and metabolic disturbances. BioMed research international, v. 2015, 2015. 
MARCHISELLO, Simona et al. Pathophysiological, molecular and therapeutic issues of nonalcoholic fatty liver disease: an overview. International journal of molecular sciences, v. 20, n. 8, p. 1948, 2019.

SANDUZZI ZAMPARELLI, Marco et al. The metabolic role of gut microbiota in the development of nonalcoholic fatty liver disease and cardiovascular disease. International journal of molecular sciences, v. 17, n. 8, p. 1225, 2016.

SIDHU, Mayenaaz et al. The gut microbiome. Australian family physician, v. 46, n. 4, p. 206, 2017.

VAN BEST, Niels; JANSEN, Peter L.; RENSEN, Sander S. The gut microbiota of nonalcoholic fatty liver disease: current methods and their interpretation. Hepatology international, v. 9, n. 3, p. 406-415, 2015.

WANG, Caihua et al. Role of Bile Acids in Dysbiosis and Treatment of Nonalcoholic Fatty Liver Disease. Mediators of inflammation, v. 2019, 2019.

XIE, Guoxiang et al. Distinctly altered gut microbiota in the progression of liver disease. Oncotarget, v. 7, n. 15, p. 19355, 2016.

Enviado: Outubro, 2020.

Aprovado: Novembro, 2020. 